2. Smith SM, Jenkinson M, Johansen-Berg $H$, et al. Tract-based spatial statistics: voxelwise analysis of multi-subject diffusion data. Neuroimage 2006;31:1487-505.

\section{S93 THE DEVELOPMENT OF A NOVEL SCALE TO SCREEN AND MEASURE ANXIETY IN PATIENTS WITH CHRONIC OBSTRUCTIVE PULMONARY DISEASE (COPD)}

doi:10.1136/thoraxjnl-2011-201054b.93

T G Willgoss, A M Yohannes, J Goldbart, F Fatoye. Manchester Metropolitan University, Manchester, UK

Introduction and objectives Comorbid anxiety disorders are common among patients with COPD, affecting up to half of all patients. Comorbid anxiety may be a significant factor in predicting quality of life, yet recognition and management of anxiety among this patient group is poor. Screening and measuring symptoms of anxiety can be challenging due to the overlap of physical symptoms and the lack of a validated disease-specific tool. The aim of this study was to develop a novel non-somatic scale (Anxiety Inventory for Respiratory disease (AIR)) to screen and measure anxiety in patients with COPD.

Methods This study utilised a multi-method approach to scale development incorporating both qualitative and quantitative methods. An item pool was developed using in-depth interviews with COPD patients who exhibited symptoms of anxiety $(n=14)$, and the analysis of existing anxiety scales. Item wording, content and user-friendliness were checked by an expert reference group (ERG) that included clinicians and patients. This item pool was tested on a group of COPD patients $(n=82)$. The Likert-type scale has four consistent responses to statements (Not at all, Occasionally, Frequently, Almost all of the time) that are scored from 0 to 3. Item and factor analysis were carried out to aid in item reduction and to explore the factor structure.

Results Sixteen items were selected for inclusion following development and approval from the ERG. Items were retained based on item-to-total correlation analysis and $\alpha$-if-item-deleted analysis. One item was discarded as it had a corrected-item-to-total correlation of $<0.55$. Exploratory principal component factor analysis was performed and three further items were removed due to low communalities $(<0.50)$. Secondary analysis indicated a single factor solution accounting for $66.67 \%$ of total variance with a mean communality of 0.67 . Abstract $S 93$ table 1 shows the factor loadings

Abstract S93 Table 1 Factor loadings for the 12-item Anxiety Inventory for Respiratory disease (AIR)

\begin{tabular}{lll}
\hline & Item & Factor 1 loading \\
\hline 1 & I have felt tense, restless or wound-up & 0.71 \\
2 & $\begin{array}{l}\text { I have found it difficult to concentrate on } \\
\text { things, such as watching TV or reading } \\
\text { I have had worrying thoughts going through } \\
\text { my mind }\end{array}$ & 0.71 \\
& I have felt frightened or very panicky & 0.83 \\
4 & I have felt worked up and/or upset & 0.85 \\
5 & I have had a fear of losing control and/or & 0.78 \\
6 & falling apart & 0.82 \\
7 & I have worried about experiencing panic & 0.88 \\
8 & I have found it hard to relax & 0.77 \\
9 & I have had sudden and intense feelings of & 0.86 \\
10 & fear and/or panic & 0.85 \\
11 & I have felt generally anxious & 0.83 \\
12 & I have had thoughts that something bad & \\
might happen & I have felt nervous or on-edge & 0.89 \\
\hline
\end{tabular}

for the final items. The 12-item scale had a mean total score of 13.55 $(\mathrm{SD}=9.41$, range $=0-36)$, and a Cronbach's $\alpha$ of 0.95 .

Conclusions The AIR is a short self-report non-somatic anxiety scale with a clear uni-dimensional factor solution and high internal consistency. Additional studies are warranted to further explore the scale's psychometric properties and to establish its ability to screen for clinical anxiety disorders.

\section{S94 ULTRASOUND MEASUREMENT OF OUADRICEPS WASTING IN EARLY CHRONIC OBSTRUCTIVE PULMONARY DISEASE AND ITS RELATIONSHIP WITH DAILY PHYSICAL ACTIVITY}

doi:10.1136/thoraxjnl-2011-201054b.94

${ }^{1} \mathrm{D}$ Shrikrishna, ${ }^{1} \mathrm{R}$ Tanner, ${ }^{2} \mathrm{~J} \mathrm{M}$ Seymour, ${ }^{1} \mathrm{M}$ Patel, ${ }^{3} \mathrm{~B}$ A Connolly, ${ }^{3} \mathrm{Z}$ A Puthucheary, ${ }^{1} \mathrm{~S}$ L F Walsh, ${ }^{1} \mathrm{~S}$ A Bloch, ${ }^{4} \mathrm{P}$ S Sidhu, ${ }^{3} \mathrm{~N}$ Hart, ${ }^{2} \mathrm{~J}$ Moxham, ${ }^{1} \mathrm{M}$ I Polkey, ${ }^{1} \mathrm{~N}$ S Hopkinson. ${ }^{1}$ National Heart and Lung Institute, NIHR Respiratory Biomedical Research Unit at Royal Brompton and Harefield NHS Foundation Trust and Imperial College, London, UK; ${ }^{2}$ Department of Asthma, Allergy \& Respiratory Science, Division of Asthma, Allergy and Lung Biology, King's College, London, UK; ${ }^{3}$ Guy's and St Thomas' NHS Foundation Trust and King's College London, National Institute of Health Research Comprehensive Biomedical Research Centre, London, UK; ${ }^{4}$ Department of Radiology, King's College Hospital, London, UK

Introduction Quadriceps weakness is recognised as an important complication of COPD but few data exist about loss of muscle bulk in early disease. We hypothesised that quadriceps wasting, measured by ultrasound rectus femoris cross-sectional (USRF $F_{C S A}$ ), would be observed in patients with mild COPD compared to healthy agematched subjects and that this would correlate with daily physical activity levels.

Methods Rectus femoris cross-sectional area was measured using ultrasound $\left(\mathrm{USRF}_{\mathrm{CSA}}\right)$ and daily physical activity (step count and physical activity level-PAL) recorded using a multisensor biaxial armband accelerometer. Fat free mass index (FFMI) and the impedance ratio $\left(Z_{200} / Z_{5}\right)$ were determined by bioelectrical impedance analysis. Quadriceps maximum voluntary contraction ( $Q M V C$ ) was used as a measure of strength

Results 150 patients with stable COPD, GOLD stage I ( $\mathrm{n}=38)$, II $(n=38)$, III $(n=37)$ and IV $(n=37)$, mean (SD) age 66 (9) years, $54 \%$ male and 40 age-matched healthy subjects participated in the study
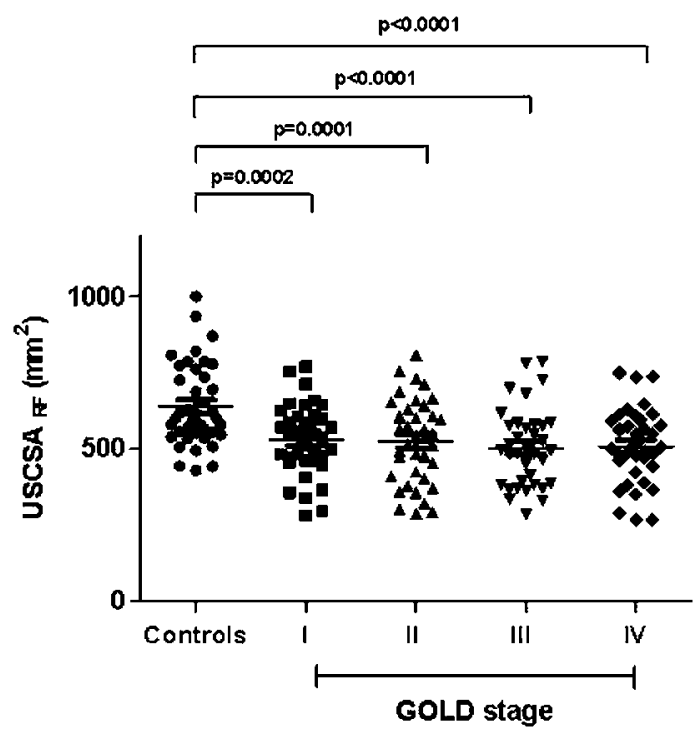

Abstract S94 Figure 1 Ultrasound rectus femoris cross-sectional area vs GOLD stage in COPD patients and healthy controls (ANOVA analysis - no significant difference between I and IV). 